\title{
Doping-Enhanced Short-Range Order of Perovskite Nanocrystals for Near-Unity Violet Luminescence Quantum Yield
}

\author{
Zi-Jun Yong, ${ }^{\dagger, I L}$ Shao-Qiang Guo, ${ }^{\ddagger}$, II Ju-Ping Ma, ${ }^{\dagger, I L}$ Jun-Ying Zhang, ${ }^{\ddagger}$, II Zhi-Yong Li, $^{\dagger}$ \\ Ya-Meng Chen, ${ }^{\dagger}$ (๑) Bin-Bin Zhang, ${ }^{\dagger}$ Yang Zhou, ${ }^{\dagger},{ }^{\circledR}$ Jie Shu, ${ }^{9}$ Jia-Li Gu, ${ }^{\|}$Li-Rong Zheng, ${ }^{\perp}$ \\ Osman M. Bakr, ${ }^{\S}$ and Hong-Tao Sun ${ }^{*},, \# \mathbb{C}$ \\ ${ }^{\dagger}$ College of Chemistry, Chemical Engineering and Materials Science, Soochow University, Jiangsu, 215123, China \\ "Department of Physics, Beihang University, Beijing, 100191, China \\ ${ }^{\S}$ Division of Physical Sciences and Engineering, King Abdullah University of Science and Technology (KAUST), Thuwal, \\ 23955-6900, Saudi Arabia \\ "Analysis and Testing Center, Soochow University, Jiangsu, 215123, China \\ ${ }^{\perp}$ Beijing Synchrotron Radiation Facility, Institute of High Energy Physics, Chinese Academy of Sciences, Beijing, 100049, China \\ ${ }^{\#}$ State Key Laboratory of Luminescence and Applications, Changchun Institute of Optics, Fine Mechanics and Physics, Chinese \\ Academy of Sciences, Changchun, 130033, China
}

\section{Supporting Information}

\begin{abstract}
All-inorganic perovskite nanocrystals (NCs) have emerged as a new generation of low-cost semiconducting luminescent system for optoelectronic applications. The room-temperature photoluminescence quantum yields (PLQYs) of these NCs in the green and red spectral range approach unity. However, their PLQYs in the violet are much lower, and an insightful understanding of such poor performance remains missing. We report a general strategy for the synthesis of allinorganic violet-emitting perovskite NCs with near-unity PLQYs through engineering local order of the lattice by nickel ion doping. A broad range of experimental characterizations, including steady-state and time-resolved lumines-

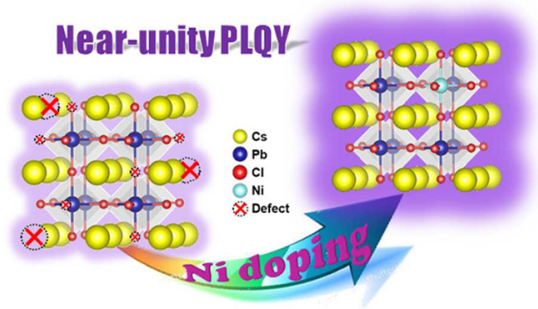
cence spectroscopy, X-ray absorption spectra, and magic angle spinning nuclear magnetic resonance spectra, reveal that the low PLQY in undoped NCs is associated with short-range disorder of the lattice induced by intrinsic defects such as halide vacancies and that $\mathrm{Ni}$ doping can substantially eliminate these defects and result in increased short-range order of the lattice. Density functional theory calculations reveal that $\mathrm{Ni}$ doping of perovskites causes an increase of defect formation energy and does not introduce deep trap states in the band gap, which is suggested to be the main reason for the improved local structural order and near-unity PLQY. Our ability to obtain violet-emitting perovskite NCs with near-perfect properties opens the door for a range of applications in violet-emitting perovskite-based devices such as light-emitting diodes, single-photon sources, lasers, and beyond.
\end{abstract}

\section{INTRODUCTION}

Lead halide perovskites have been established as a new generation of low-cost semiconducting materials for photovoltaic devices owing to their outstanding optoelectronic properties. ${ }^{1-7}$ The efficiency of perovskite solar cells has risen dramatically from $3.8 \%$ to over $22 \%$ in the past several years owing to concentrated efforts on the optimization of perovskite layers and device structures, interfacial engineering, and so on. ${ }^{4}$ In parallel with photovoltaic application, lead halide perovskites, in particular all-inorganic $\mathrm{CsPbX}_{3}(\mathrm{X}=$ halide ions) nanocrystals (NCs), are emerging as a family of promising light emitters owing to their size- and composition-dependent tunable band gaps from the violet to near-infrared and extremely narrow full width at half-maximum (fwhm) ${ }^{8-24}$ The photoluminescence quantum yields (PLQYs) of $\mathrm{CsPbBr}_{3}$ and $\mathrm{CsPbI}_{3} \mathrm{NCs}$ can reach over $90 \%$ in the green and red spectral ranges, respectively, and high-efficiency light-emitting diodes and low-threshold amplified spontaneous emission have been accomplished by using such $\mathrm{NCs}$ as emissive layers. ${ }^{14,21,24}$ By contrast, $\mathrm{CsPbX}_{3}$ NCs exhibit lower PLQYs in the violet, and PLQYs are limited to be less than $65 \%{ }^{23}$ So far, the exact underlying mechanism for low PLQYs in these $\mathrm{NCs}$ has not been fully understood, significantly limiting the rational design of perfect $\mathrm{NCs}$ and thus hampering their applications for violet-emitting devices. Considering the lowcost processing of $\mathrm{CsPbX}_{3} \mathrm{NCs}$ and limited violet-emitting material systems available, it is believed that obtaining highefficiency violet luminescent $\mathrm{CsPbX}_{3} \mathrm{NCs}$ would provide an alternative candidate for violet-emitting devices.

Impurity doping has been demonstrated as one powerful method for introducing novel functionalities into traditional

Received: May 6, 2018

Published: July 16, 2018 

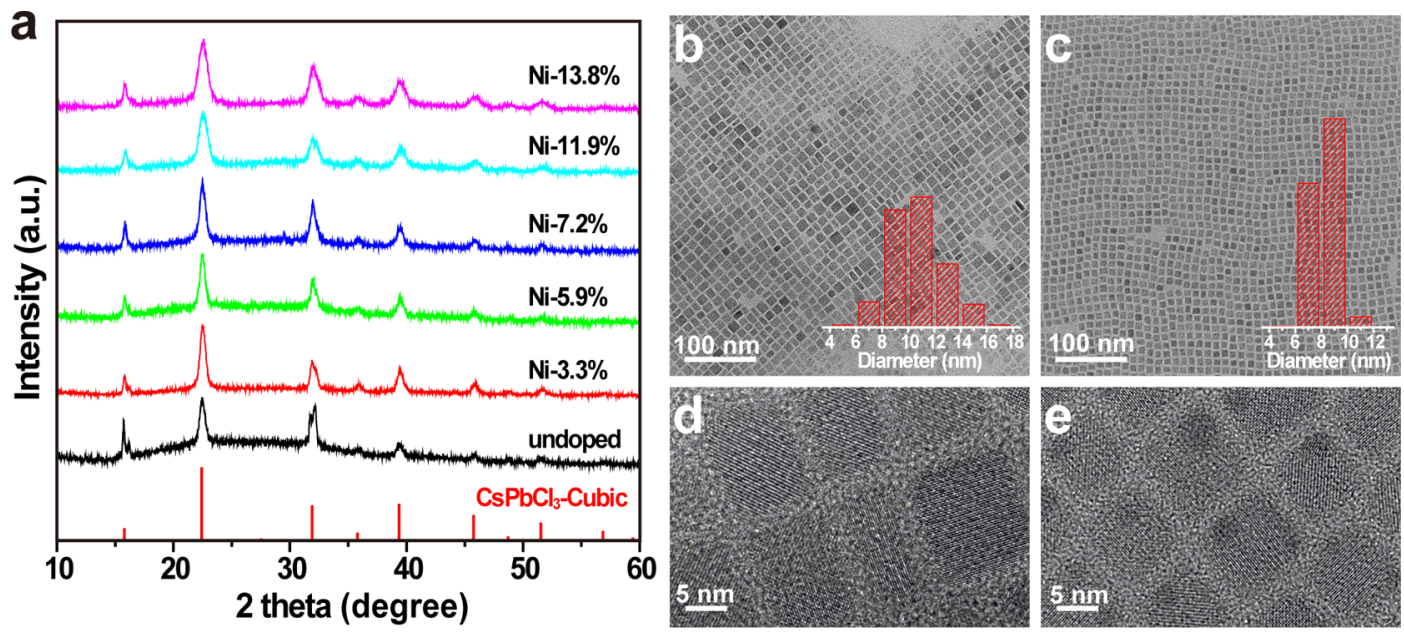

Figure 1. Structure and morphology of undoped and doped $\mathrm{CsPbCl}{ }_{3} \mathrm{NCs}$. (a) Powder $\mathrm{XRD}$ patterns of undoped and doped $\mathrm{CsPbCl} \mathrm{NCs}_{3} \mathrm{Nhe}$ standard diffraction of cubic CsPbCl is drawn using red vertical lines. (b, c) Low-magnification TEM images of (b) undoped NCs and (c) Ni$11.9 \%$. Insets of (b) and (c) show the histograms of edge lengths of corresponding $\mathrm{CsPbCl}_{3} \mathrm{NCs}$. (d, e) High-resolution TEM images of (d) undoped NCs and (e) Ni-11.9\%.
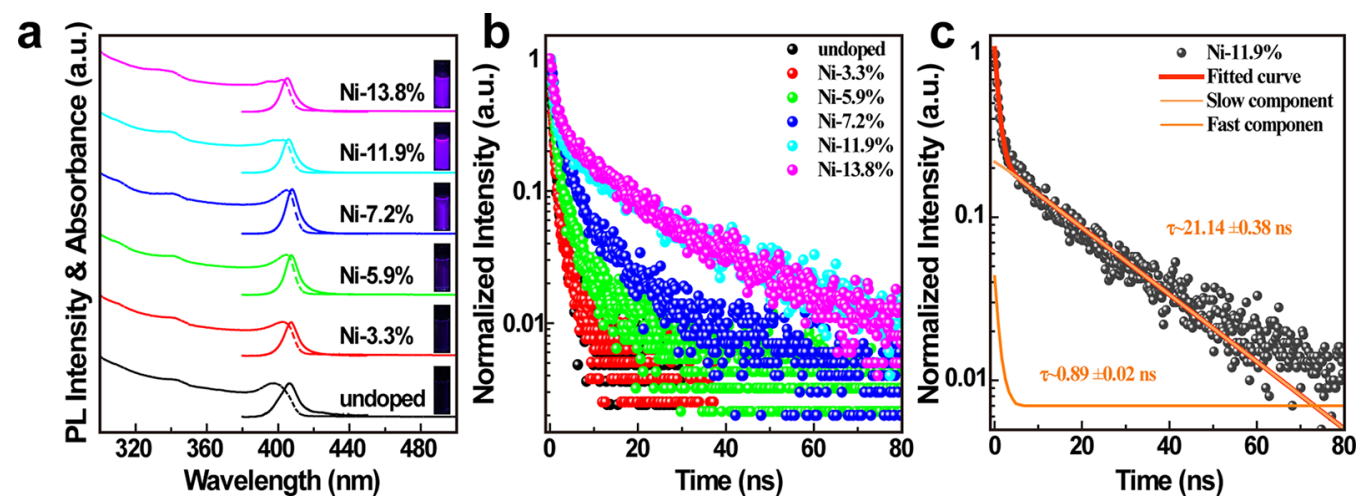

Figure 2. Optical properties of undoped and doped $\mathrm{CsPbCl}_{3}$ NCs. (a) Absorption and PL spectra of undoped and doped $\mathrm{CsPbCl}{ }_{3} \mathrm{NCs}$ Inset shows the photographs of NC solution under UV $(365 \mathrm{~nm})$ illumination; the absorption of all NC solutions was adjusted to an optical density of 0.08. (b) PL decay traces of undoped and doped $\mathrm{CsPbCl}_{3}$ NCs. (c) PL decay trace of Ni-11.9\%, showing a fast $(\sim 0.89 \mathrm{~ns})$ and a slow $(\sim 21.14 \mathrm{~ns})$ component.

II-VI and III-V NCs, where it is used to impart p- and n-type behaviors, magnetism, and impurity-related PL. ${ }^{25-28}$ For instance, doping of $\mathrm{ZnSe} \mathrm{NCs}$ with $\mathrm{Mn}^{2+}$ gives rise to intense sensitized $\mathrm{Mn}^{2+}$ luminescence and creates a magnetically coupled exciton state enabling optical control of magnetism. ${ }^{25-27}$ Doping of heterovalent ions such as $\mathrm{Bi}^{3+}$ and rareearth ions or isovalent ions such as $\mathrm{Mn}^{2+}$ into lead halide perovskites has also been studied, which results in the occurrence of new emission bands attributed to dopant-related emitters. $^{29-42}$ The common PL feature of these doped perovskites lies in the existence of energy transfer from the charge carriers of hosts to dopants (i.e., doped NCs show dualcolor emission), thus resulting in a significant constraint on attaining a near-unity PLQY for the band-edge emission.

We reasoned that the origin of the low PLQY in violetemitting $\mathrm{CsPbX}_{3}$ NCs could be attributed to the imperfect assembly of constituents during the reaction, giving rise to a large amount of structural defects that are challenging to eliminate merely by tailoring the synthetic factors such as reaction temperature and duration, precursors, and stoichiometry of reactants. The defects, probably vacancies and/or distorted $\left[\mathrm{PbX}_{6}\right]$ octahedra, could deteriorate the short-range order of the lattice and act as trapping centers of photo- generated carriers, thus giving rise to poor PLQYs for the band-edge emission. We therefore hypothesized that, if incorporating some judiciously selected foreign ions into the $\mathrm{CsPbX}_{3}$ matrix could substantially increase the defect formation energy and thus enhance the short-range order of the lattice, while not introducing new recombination channels, it could offer an opportunity for significant enhancement of single-color band-edge emission.

Here, we develop a general strategy for the synthesis of violet-emitting $\mathrm{CsPbX}_{3} \mathrm{NCs}$ with near-unity PLQY through nickel $(\mathrm{Ni})$ doping. We chose $\mathrm{Ni}$ ions as dopants with the idea that it has a strong preference for octahedral coordination with halide ions. ${ }^{43}$ We first illustrate our design concept by doping $\mathrm{Ni}$ ions into $\mathrm{CsPCl}_{3} \mathrm{NCs}$. We find that the incorporation of $\mathrm{Ni}^{2+}$ ions into $\mathrm{CsPbCl}_{3} \mathrm{NCs}$ leads to strong single-color violet emission with a maximum PLQY of $96.5 \%$, which, to the best of our knowledge, represents the highest value in this spectral region among lead halide perovskites reported. A wide range of experimental characterizations reveal that the key for the success is that doping of $\mathrm{Ni}^{2+}$ ions substantially removes structural defects and results in improved short-range order of the perovskite lattice. All these observations can be well explained by density functional theory (DFT) calculations, 

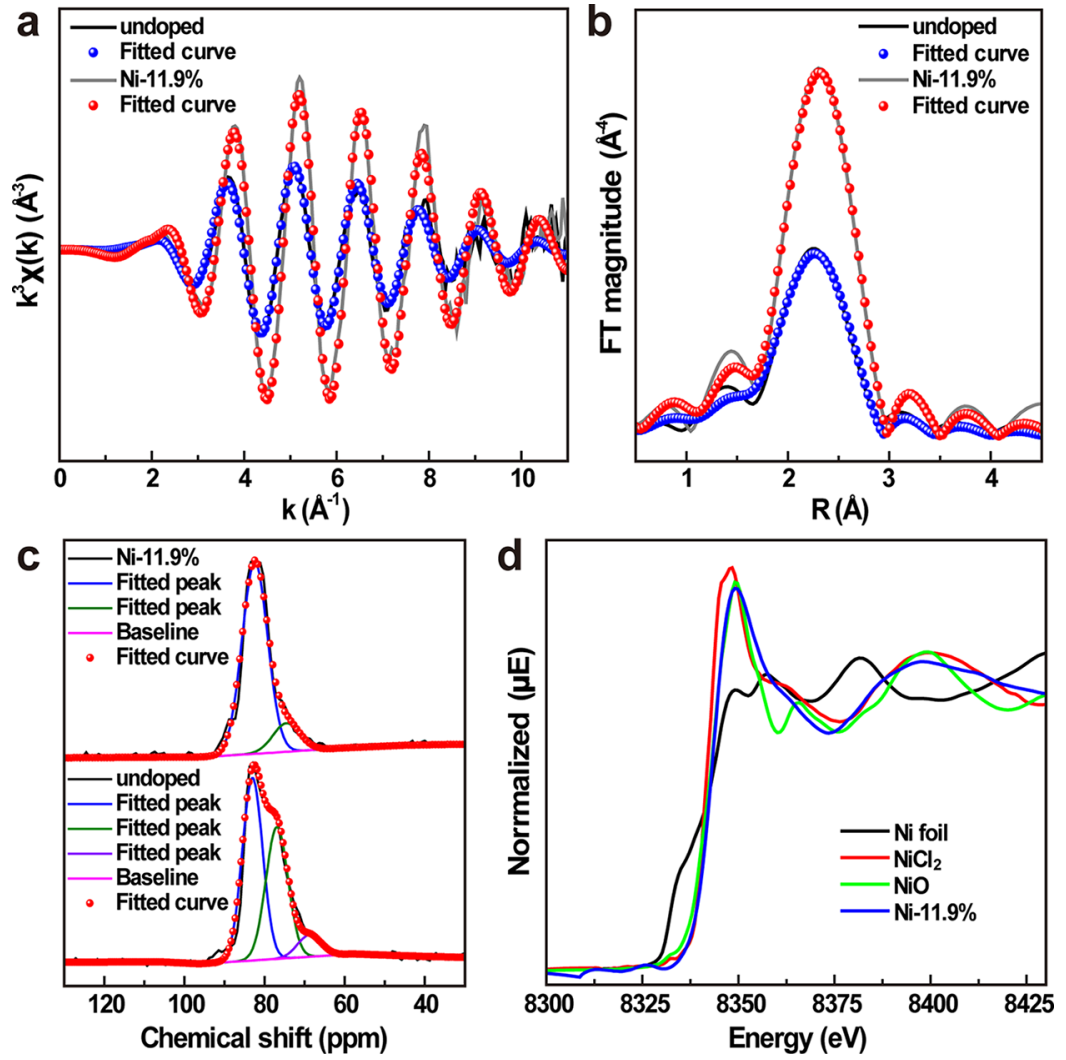

Figure 3. Local structure characterizations of undoped and doped $\mathrm{CsPbCl}_{3} \mathrm{NCs}$. (a) $k_{3}$-weighted $\mathrm{Pb} \mathrm{L}_{\mathrm{III}}$-edge EXAFS and (b) corresponding Fourier transforms (FTs) of undoped and Ni-11.9\% NCs. (c) Solid-state ${ }^{133} \mathrm{Cs}$ MAS NMR spectra of undoped and Ni-11.9\% NCs. (d) Ni K-edge XANES spectra of $\mathrm{Ni}-11.9 \%, \mathrm{Ni}$ foil, $\mathrm{NiCl}_{2}$, and $\mathrm{NiO}$.

which reveal that doped NCs feature increased defect formation energy with respect to undoped cousins. Interestingly and importantly, the concept of doping-enhanced lattice order shown here is sufficiently general to significantly boost PLQYs of other perovskite NCs, thus paving the way for the use of these NCs for violet-emitting devices.

\section{RESULTS AND DISCUSSION}

We first used $\mathrm{CsPbCl}_{3} \mathrm{NCs}$ as a model system to exemplify our strategy. We synthesized $\mathrm{Ni}$-doped $\mathrm{CsPbCl}_{3} \mathrm{NCs}$ by a modified hot-injection method as first reported by Protesescu et al. ${ }^{15}$ To quantify Ni incorporation in the resultant NCs, we used inductively coupled plasma mass spectroscopy (ICP-MS). It is found that the concentration of incorporated $\mathrm{Ni}$ increases as a function of the amount of $\mathrm{NiCl}_{2}$ precursor used (Table S1). The high-resolution transmission electron microscopy (TEM) images, coupled with the elemental mapping by energy-dispersive X-ray spectroscopy (EDS), show that Ni ions are incorporated into the perovskite lattice (Figure S1). Hereafter, the products are denoted $\mathrm{Ni}-x \%$ according to the molar ratio of $\mathrm{Ni}$ to $\mathrm{Pb}$ determined by ICP-MS. Powder X-ray diffraction (XRD) patterns confirm that both undoped and doped NCs adopt a cubic phase of the space group $P m \overline{3} \mathrm{~m}$ (221) (Figure 1a). ${ }^{15}$ We note that, although both undoped and doped NCs show a clear lattice fringe, Ni doping could influence the size and uniformity of NCs, as revealed by lowmagnification and high-resolution TEM (Figure $1 \mathrm{~b}-\mathrm{e}$ ). As the $\mathrm{Ni}$ concentration increases, the average side length of NCs decreases from $10.6 \mathrm{~nm}$ to $8.3 \mathrm{~nm}$, and the size distribution of NCs becomes narrowed (Figure 1b,c and Figure S2).
Figure 2a displays the absorption and PL spectra of undoped and doped $\mathrm{CsPbCl}_{3} \mathrm{NCs}$. We note that no new absorption bands are introduced by $\mathrm{Ni}$ doping and that the exciton absorption of NCs first shifts very slightly to the red and then to the blue with increasing $\mathrm{Ni}$ concentration, evidencing the weak effect of $\mathrm{Ni}$ doping on the electronic structure of the host (Figure S3). Interestingly, $\mathrm{Ni}$ doping causes substantially enhanced band-edge emission of $\mathrm{CsPCl}_{3} \mathrm{NCs}$ (inset of Figure $2 a)$. We find that the PLQY is greatly improved upon $\mathrm{Ni}$ doping, from $2.4 \%$ for the undoped NCs to $96.5 \%$ for Ni$11.9 \%$ (Figure S4, Table S2), signifying that there is negligible nonradiative recombination occurring in Ni-11.9\%. To the best of our knowledge, this represents the highest PLQY among violet-emitting halide perovskites. ${ }^{23}$ Different from $\mathrm{Bi}^{3+}$ - and $\mathrm{Mn}^{2+}$-doped $\mathrm{CsPbX}_{3}$, our Ni-doped NCs do not show any dopant-related $\mathrm{PL}$ at room or cryogenic temperature in the visible and infrared spectral range. ${ }^{33,34}$ Additionally, we also observed a dopant-concentration-dependent PL shift similar to the trend of the absorption (Figure S5), which is accompanied by decreased fwhm's for the doped NCs. The possible source for the spectral shift may be associated with size change upon doping, which probably causes minor alteration of the absorbing and emitting states in NCs, as theoretically revealed in $\mathrm{CsPbX}_{3} \mathrm{NCs}^{44,45}$ The decreased fwhm's of PL for doped NCs can be attributed to the uniform size distribution of NCs. We note that Ni doping does not deteriorate the PL stability of NCs with respect to undoped cousins, and the morphology of doped NCs remains almost unchanged when exposed in ambient environment (Figure S6).

To know more photophysical properties of these NCs, we carried out time-resolved PL measurement, given that it can 
Table 1. Main Fitting Results of the Fit Performed on the $\mathrm{Pb} \mathrm{L}_{\mathrm{III}}$-Edge $\boldsymbol{k}^{3}$-Weighted EXAFS Spectra for Undoped CsPbCl $\mathrm{NCs}_{3}$ and $\mathrm{Ni}-11.9 \%$

$\begin{array}{cccccc}\text { sample } & \text { shell } & \mathrm{CN}^{a} & \Delta E_{0}(\mathrm{eV})^{b} & \sigma^{2}\left(\AA^{2}\right)^{c} & R(\AA)^{d} \\ \text { undoped } & \mathrm{Pb}-\mathrm{Cl} & 3.7 \pm 0.8 & -4.0 \pm 2.1 & 0.018 \pm 0.003 & 2.84 \pm 0.02 \\ \text { Ni-11.9\% } & \mathrm{Pb}-\mathrm{Cl} & 5.1 \pm 0.7 & 0.2 \pm 1.3 & 0.014 \pm 0.002 & 0.0084\end{array}$

${ }^{a}$ The fitted coordination number. ${ }^{b}$ The energy shift. ${ }^{c}$ The mean-square relative displacement of absorber and backscatter atoms. ${ }^{d}$ Distance between absorber and backscatter atoms.

provide information on the transient evolution of the photogenerated carriers. Figure $2 \mathrm{~b}$ displays the decay curves of undoped and doped NCs, where the excitation wavelength is $373 \mathrm{~nm}$ and the excitation energy density is $4.0 \mu \mathrm{J} / \mathrm{cm}^{2}$. We note that the PL kinetics becomes slower upon Ni doping from $3.3 \%$ to $11.9 \%$ and that incorporating $\mathrm{Ni}$ ions over $11.9 \%$ leads to faster decay. All decay curves were fitted by a multiexponential function (Figure 2c, Figure S7, and Table S2). The relative contribution of fast and slow components to the steady-state PL can be evaluated by integrating the respective exponential traces, which shows that the fast component amounts to $16.4 \%$ of the total signal for Ni-11.9\%. The longest calculated average lifetime is $18.39 \mathrm{~ns}$ for $\mathrm{Ni}-11.9 \%$. We also evaluated the radiative and nonradiative decay rates that were estimated from the PLQYs and the average lifetimes (Table S2). ${ }^{23}$ Notably, the nonradiative recombination rate decreases from $378.29 \mu \mathrm{s}^{-1}$ in undoped NCs to $1.90 \mu \mathrm{s}^{-1}$ in Ni-11.9\%, evidencing that $\mathrm{Ni}$ doping favors the suppression of nonradiative recombination.

To gain deep insight into the $\mathrm{Ni}$-doping-induced giant enhancement of band-edge emission from NCs, we took the extended X-ray absorption fine structure (EXAFS) spectra at the $\mathrm{Pb} \mathrm{L} \mathrm{L}_{\mathrm{III}}$-edge for typical samples. As is well known, EXAFS is a powerful technique for the examination of the local coordination environment and local order around the absorbing atoms. ${ }^{46}$ The $k_{3}$-weighted $\mathrm{Pb} \mathrm{L}_{\mathrm{III}}$-edge EXAFS and the corresponding Fourier transforms (FTs) of undoped and doped $\mathrm{CsPbCl}_{3} \mathrm{NCs}$ are shown in Figure 3a,b. Both samples demonstrate one peak centered at ca. $2.3 \AA$ (the distance not phase corrected) in $R$ space, which can be attributed to the single scattering of photoelectrons by chloride atoms (Figure $3 b)$. The absence of other peaks in $R$ space is due to the lack of long-range structural coherence in $\mathrm{CsPbCl}_{3} \mathrm{NCs}$, which was also observed in other doped NCs. ${ }^{46}$ Interestingly, we find that the doped $\mathrm{CsPbl}_{3} \mathrm{NCs}$ show a stronger amplitude in $R$ space with respect to the undoped counterpart, suggesting improved order of the local coordination environment of $\mathrm{Pb}$. To obtain more information concerning the doping-induced variation of the local environment of $\mathrm{Pb}$, we performed a single-shell fit of both EXAFS spectra over an $R$ range of 1.5-3.0 $\AA$. In both cases, four parameters were varied in the model: the coordination number $(\mathrm{CN})$, the energy shift $\left(\Delta E_{0}\right)$, the adjustment of the half path length $(\Delta R)$, and the mean-square relative displacement of absorber and backscatter atoms $\left(\sigma^{2}\right)$. Based on the fitting results of EXAFS spectra (Figure $3 \mathrm{a}, \mathrm{b}$ and Table 1$)$, a smaller $\sigma^{2}\left(0.014 \AA^{2}\right)$ is observed in doped NCs than in undoped cousins $\left(0.018 \AA^{2}\right)$. Since this factor is a reflection of mean-square disorder in the distribution of interatomic distances, we conclude that $\left[\mathrm{PbCl}_{6}\right]$ octahedra are heavily disordered in undoped NCs and that Ni doping leads to improved order of the lattice. ${ }^{47}$ Although the EXAFS analysis typically gives an uncertainty of $\pm 20 \%$ in the determination of the $\mathrm{CN}$, the fitted $\mathrm{CN}$ of $\mathrm{Pb}$ with chloride atoms increases upon $\mathrm{Ni}$ doping (Table 1$).{ }^{48}$ This, to some extent, suggests that $\mathrm{Ni}$ doping can inhibit the formation of chloride vacancies. Collectively, these data provide strong evidence that $\mathrm{Ni}$ doping is favorable for the suppression of structural defects of $\mathrm{Cs} \mathrm{PbCl}_{3} \mathrm{NCs}$, resulting in a more ordered perovskite lattice. Additionally, we find that the onset of the absorption for the $\mathrm{Pb} \mathrm{L}_{\mathrm{III}}$-edge $\mathrm{X}$-ray absorption near-edge structure (XANES) does not show a remarkable variation upon $\mathrm{Ni}$ doping, signifying that the oxidation state of $\mathrm{Pb}$ is virtually the same for both undoped and doped samples (Figure S8).

Considering that the ${ }^{133} \mathrm{Cs}$ nucleus is highly sensitive to its local environment, we further took solid-state ${ }^{133} \mathrm{Cs}$ MAS (magic angle spinning) NMR spectra of these samples to obtain more information concerning the effect of $\mathrm{Ni}$ doping on the $\mathrm{CsPbCl}_{3}$ structure. $^{49,50}$ As shown in Figure $3 \mathrm{c}$, it is observed that the undoped NCs possess a broader Cs signal with respect to $\mathrm{Ni}-11.9 \%$, providing direct evidence of improved crystal quality of doped NCs. The spectrum of Ni$11.9 \%$ can be deconvoluted into three peaks at $83.0,76.9$, and $68.8 \mathrm{ppm}$, suggesting that $\mathrm{Cs}$ atoms are mainly in three chemical states and environments. We surmise that the strongest peaks at $83.0 \mathrm{ppm}$ can be attributed to Cs coordinated with 12 chloride atoms (i.e., the peak corresponds to Cs in a regular coordination geometry), and the latter two to Cs atoms coordinated to fewer chloride atoms and/or in distorted local environments induced by chloride vacancies. $^{49,50}$ It is noted that the sum of the intensity for the peaks at 76.9 and $68.8 \mathrm{ppm}$ are comparable to that at 83.0 ppm, suggesting the existence of considerable amounts of chloride vacancy-related defects in undoped NCs. In contrast, $\mathrm{Ni}-11.9 \%$ shows a signal peaking at $82.4 \mathrm{ppm}$, accompanied by a very weak peak at $74.5 \mathrm{ppm}$, evidencing much fewer chloride vacancies.

Taking all these structural analyses together, we establish that Ni doping can greatly suppress the formation of structural defects such as chloride vacancies and that the Ni-dopinginduced increase in PLQYs can be associated with increased short-range order of the $\mathrm{CsPCl}_{3}$ lattice. To examine the oxidation state and the local coordination environment of $\mathrm{Ni}$, we next took Ni K-edge X-ray absorption spectra of $\mathrm{Ni}-11.9 \%$, $\mathrm{Ni}$ foil, $\mathrm{NiCl}_{2}$, and $\mathrm{NiO}$. As seen in the XANES spectra (Figure $3 \mathrm{~d}$ ), the doped NCs show a similar onset of absorption to those of $\mathrm{NiCl}_{2}$ and $\mathrm{NiO}$, indicating that the oxidation state of $\mathrm{Ni}$ is +2 . We also note that $\mathrm{Ni}-11.9 \%$ shows a relatively symmetric white line near $8350 \mathrm{eV}$, akin to $\mathrm{NiCl}_{2}$ and $\mathrm{NiO}$ reference samples, which is a characteristic spectral feature of $\mathrm{Ni}^{2+}$ in octahedral coordination. ${ }^{51}$ It is expected that EXAFS can provide more detailed information regarding the coordination environment of $\mathrm{Ni}^{2+}$ in $\mathrm{CsPbCl}_{3}$, but unfortunately it is found that the $\mathrm{Ni}_{\mathrm{III}}$-edge EXAFS spectrum taken at room temperature shows rather noisy signals in $k$ space (Figure S9). This may be caused by strong absorption of the fluorescence signal of $\mathrm{Ni}$ by $\mathrm{Cs}$ and $\mathrm{Pb}$ and/or by the large disorder of $\mathrm{Ni}$ in $\mathrm{CsPbCl}_{3}$ that may result from the large 

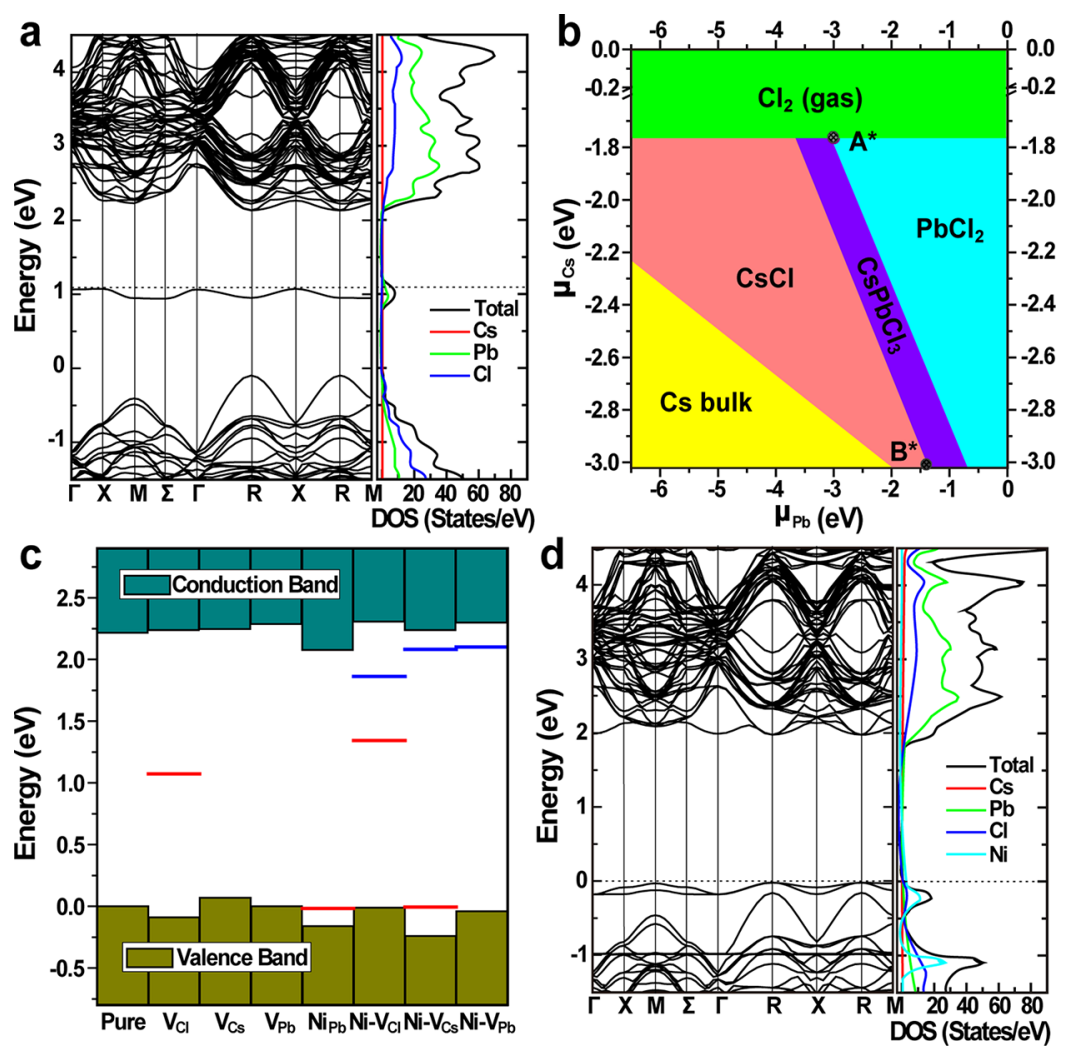

Figure 4. DFT calculations of the band structure, DOS, stability regions of different compounds, and defect levels. (a) Band structure and DOS of undoped $\mathrm{CsPCl}_{3}$ with a $\mathrm{Cl}$ vacancy. The horizontal dotted line represents the Fermi level. (b) Stability regions of different compounds against Cs and $\mathrm{Pb}$ chemical potentials. (c) Defect levels for both pure and doped $\mathrm{CsPCl}_{3}$. The red lines represent the highest defect level under the Fermi level, whereas the blue lines represent the lowest defect level above the Fermi level. The values of VBM, CBM, and defect levels derive from the corresponding band structures. (d) Band structure and DOS of Ni-doped $\mathrm{CsPbl}_{3}$ without any defect. The horizontal dotted line represents the Fermi level.

difference in ionic radii of $\mathrm{Ni}$ and $\mathrm{Pb}$ (six-coordinate ionic radii are 119 and $69 \mathrm{pm}$ for $\mathrm{Pb}^{2+}$ and $\mathrm{Ni}^{2+}$, respectively). ${ }^{47,52}$

It is well known that the mean-square relative displacement of absorber and backscatter atoms $\left(\sigma^{2}\right)$ determined by EXAFS experiments is composed of two contributions: a thermal contribution and a static disorder contribution. ${ }^{47 a}$ The former is intimately associated with the temperature, which can be partially suppressed by decreasing the temperature of the sample. ${ }^{47 a}$ To know more information regarding $\mathrm{Ni}$ ions in NCs, we then obtained the low-temperature Ni K-edge X-ray absorption spectrum. The $k_{2}$-weighted $\mathrm{Ni} \mathrm{K}$-edge EXAFS and the corresponding FT of Ni-11.9\% are shown in Figure S10a, b. It is well recognized that the peak in $R$ space corresponds to the interatomic distances between absorbing and surrounding atoms. Because of photoelectron phase shift, the peak position in the FT decreases by $0.2-0.5 \AA$ relative to the actual interatomic distance. ${ }^{47 \mathrm{~b}, \mathrm{c}}$ We note that there is a peak located at about $2.5 \AA$ (the distance not phase corrected) in $R$ space (Figure $\mathrm{S} 10 \mathrm{~b}$ ), which is comparable to the bond length of $\mathrm{Pb}-$ $\mathrm{Cl}$ in $\mathrm{CsPbCl}_{3}$ but much larger than that of $\mathrm{Ni}-\mathrm{Cl}$ in nickel chloride, after considering the photoelectron phase shift. This result, combined with other experimental facts including the doping-induced significant change of the local environments of $\mathrm{Pb}$ and $\mathrm{Cs}$ and the octahedral coordination of $\mathrm{Ni}^{2+}$ ions, signifies that an isovalent substitution of $\mathrm{Ni}$ for $\mathrm{Pb}$ occurs, resulting in a larger bond length of $\mathrm{Ni}-\mathrm{Cl}$ in doped $\mathrm{CsPbCl}_{3}$ compared with those of nickel chloride. ${ }^{43}$ We stress that at present it is still challenging to know the exact distribution of
$\mathrm{Ni}$ ions in NCs, which remains an open question for further research.

We next performed DFT calculations aimed at understanding the origin of $\mathrm{Ni}$-doping-induced changes in structural and photophysical properties of $\mathrm{CsPbCl}_{3} \mathrm{NCs}$. All calculations were carried out using the Vienna ab initio simulation package (VASP) with projector augmented wave (PAW) potentials. $^{53,54}$ The electronic band structures, density of states (DOS), stability region of different compounds against $\mathrm{Cl}$ and $\mathrm{Pb}$ chemical potentials, the defect formation energy, crystal formation energy, and defect levels for both undoped and doped $\mathrm{CsPbCl}_{3}$ were calculated (see details in the Experimental Section). As illustrated in Figure S11, both the valence band maximum (VBM) and the conduction band minimum (CBM) of pristine $\mathrm{CsPbCl}_{3}$ are located at the $R$ point, corresponding to a calculated band gap of $2.11 \mathrm{eV}$, $\sim 0.77 \mathrm{eV}$ smaller than the experimental value of $2.88 \mathrm{eV}$, as standard DFT generally underestimates the gap value. ${ }^{44} \mathrm{We}$ note that the states around the band gap come from $\mathrm{Pb}$ and $\mathrm{Cl}$ atoms, while Cs has no contribution (Figure S11). Interestingly, undoped $\mathrm{Cs} \mathrm{PbCl}_{3}$ with $\mathrm{Cl}$ vacancy possesses an in-gap state, although its band gap remains almost unchanged (Figure $4 \mathrm{a}$ ). For undoped $\mathrm{CsPbCl}_{3}$, both $\mathrm{Pb}$ and $\mathrm{Cs}$ vacancies cannot affect the band gap and no in-gap states are introduced (Figures S12, S13). Since the defect formation energy depends on the chemical potentials of the constitute atoms, there is a certain region of chemical potentials in which pure $\mathrm{CsPbCl}$ is stable under thermal equilibrium growth conditions. ${ }^{55} \mathrm{We}$ 
calculated the available equilibrium chemical potential region for $\mathrm{CsPbCl}_{3}$ by considering all limitations required and find that the region is narrow (Figure 4b). We next mainly considered the intrinsic point defects in pure (undoped) and doped $\mathrm{CsPbCl}_{3}$, namely, atomic vacancies $\left(\mathrm{V}_{\mathrm{Cl}}, \mathrm{V}_{\mathrm{Pb}}\right.$, and $\mathrm{V}_{\mathrm{Cs}}$ in pure $\mathrm{CsPbCl}_{3}$ and $\mathrm{Ni}-\mathrm{V}_{\mathrm{Cl}}, \mathrm{Ni}-\mathrm{V}_{\mathrm{Pb}}$, and $\mathrm{Ni}-\mathrm{V}_{\mathrm{Cs}}$ in doped $\left.\mathrm{CsPCl}_{3}\right)$ and substitutional defects $\left(\mathrm{Ni}_{\mathrm{Pb}}\right)$. Two points $\mathrm{A}^{*}$ and $\mathrm{B}^{*}$ in Figure $4 \mathrm{~b}$ were chosen to calculate the formation energies of these defects. The $\mathrm{A}^{*}$ point corresponds to the $\mathrm{Cl}$ rich/ $\mathrm{Pb}$-poor condition, whereas the $\mathrm{B}^{*}$ point to $\mathrm{Cl}$-poor/ $\mathrm{Pb}$ rich condition. In both cases we find that the formation energy of $\mathrm{V}_{\mathrm{Pb}}$ is much larger than those of $\mathrm{V}_{\mathrm{Cl}}$ and $\mathrm{V}_{\mathrm{Cs}}$, suggesting $\mathrm{V}_{\mathrm{Cl}}$ and $\mathrm{V}_{\mathrm{Cs}}$ as the dominant defects in $\mathrm{CsPbl}_{3}$ (Table 2). We

Table 2. Calculated Formation Energies (in eV) for Defects in $\mathrm{CsPbCl}_{3}$ at the Two Chosen Points $\mathrm{A}^{*}$ and $\mathrm{B}^{*}$ in Figure $4 \mathrm{~b}$

\begin{tabular}{lccccccc} 
& & & & & $\mathrm{Ni}-$ & $\mathrm{Ni}-$ & $\mathrm{Ni}-$ \\
$\mathrm{V}_{\mathrm{Cl}}$ & $\mathrm{V}_{\mathrm{Cs}}$ & $\mathrm{V}_{\mathrm{Pb}}$ & $\mathrm{Ni}_{\mathrm{Pb}}$ & $\mathrm{V}_{\mathrm{Cl}}$ & \multicolumn{1}{c}{$\mathrm{V}_{\mathrm{Cs}}$} & $\mathrm{V}_{\mathrm{Pb}}$ \\
Cl-rich & 2.378 & 1.292 & 4.089 & 1.239 & 3.197 & 2.755 & 5.426 \\
Cl-poor & 1.237 & 2.433 & 3.582 & -4.408 & -3.231 & -1.931 & 4.412 \\
\hline
\end{tabular}

also note that $\mathrm{Ni}$ readily substitutes for $\mathrm{Pb}$ under $\mathrm{Cl}$-rich and $\mathrm{Cl}$-poor conditions. Importantly, under $\mathrm{Cl}$-rich conditions (i.e., an experimental condition used for our synthesis), Ni doping can notably increase the formation energy of $\mathrm{V}_{\mathrm{Cl}}, \mathrm{V}_{\mathrm{Cs}}$, and $\mathrm{V}_{\mathrm{Pb}}$. This suggests that $\mathrm{Ni}$ doping into $\mathrm{CsPbCl}_{3}$ favors the suppression of these defects, agreeing well with the experimental results. We note that, under Cl-rich conditions, the crystal formation energy of Ni-doped $3 \times 3 \times 3 \mathrm{CsPbCl}_{3}$ supercells is $1.239 \mathrm{eV}$ larger than that of their undoped cousin. This suggests that doping of $\mathrm{Ni}$ in the $\mathrm{CsPbCl}_{3}$ lattice can potentially decrease the growth rate of NCs, thus resulting in a smaller size of doped NCs (Figure $1 \mathrm{~b}, \mathrm{c}$ ), although the $\mathrm{Ni}$ source in the reaction system may also influence the growth process of NCs (e.g., affecting nucleation of NCs).

The defect levels for both undoped and doped $\mathrm{CsPbCl}_{3}$ are shown in Figure $4 \mathrm{c}$. Obviously, $\mathrm{V}_{\mathrm{Cl}}$ and $\mathrm{Ni}-\mathrm{V}_{\mathrm{Cl}}$ can introduce deep defect levels, and all others show shallow levels or the absence of in-gap defect levels. We underscore that this is in sharp contrast with the case of $\mathrm{CsPBr}_{3}, \mathrm{CsPbI}_{3}$, and hybrid bromide/iodide perovskites, in which the halide vacancy introduces a shallow defect level. ${ }^{55-57}$ As is recognized, deep defect levels can act as carrier traps, resulting in nonradiative recombination, whereas shallow levels largely preserve the bulk electronic band structure and do not degrade the optoelectronic properties. ${ }^{55}$ On the basis of the calculations of the band structure and DOS of $\mathrm{Ni}$-doped $\mathrm{CsPbCl}_{3}$ without defects, we can see that the band gap is almost unchanged with respect to pristine $\mathrm{CsPbCl}_{3}$ and a localized energy state associated with $\mathrm{Ni}$ dopant near the VBM appears (Figure 4d). We note that the band-edge emission of $\mathrm{CsPbCl}_{3} \mathrm{NCs}$ is of excitonic nature, which can be viewed as the recombination of an excited electron with self-trapped hole. ${ }^{45}$ In light of high-efficiency PL from doped NCs, we surmise that Ni doping could not greatly influence the state of a self-trapped hole, although it is possible to slightly affect the light absorption behavior (Figure S3). We note that the influence of $\mathrm{Ni}$ doping on the electronic structure of $\mathrm{CsPbCl}_{3} \mathrm{NCs}$ merits a more detailed study and will be shown in our future work. The above theoretical results highlight the important role of $\mathrm{V}_{\mathrm{Cl}}$ in limiting the optoelectronic performance of $\mathrm{CsPCl}_{3}$ and suggest that the benefit of $\mathrm{Ni}$ doping lies in the increased defect formation energies that can result in improved crystal quality of $\mathrm{CsPbCl}_{3}$ NCs. All these are consistent with the enhanced short-range
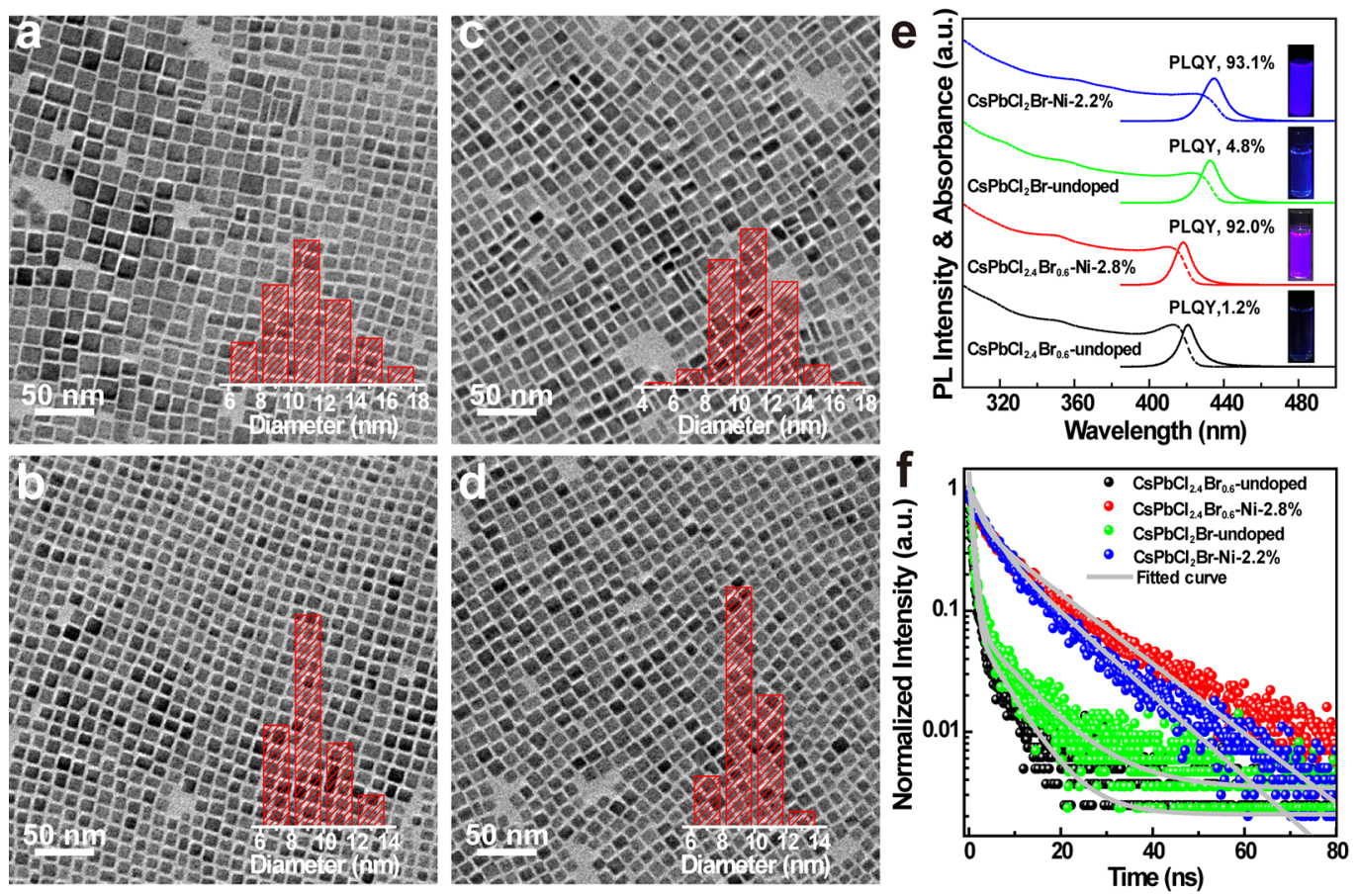

Figure 5. Morphology and optical properties of undoped and doped $\mathrm{CsPb}(\mathrm{Cl}, \mathrm{Br})_{3} \mathrm{NCs}$. (a, b) Low-magnification TEM images of (a) undoped and (b) doped $\mathrm{CsPbCl}_{2.4} \mathrm{Br}_{0.6} \mathrm{NCs}$. (c, d) Low-magnification TEM images of (c) undoped and (d) doped $\mathrm{CsPbCl}_{2} \mathrm{Br} \mathrm{NCs}$. Insets of (a) - (d) show the histograms of edge lengths of corresponding $\mathrm{CsPbX}_{3} \mathrm{NCs}$. (e) Absorption and PL spectra of undoped and doped $\mathrm{CsPb}(\mathrm{Cl}, \mathrm{Br})_{3} \mathrm{NCs}$. Inset shows the photographs of an NC solution under $\mathrm{UV}(365 \mathrm{~nm})$ illumination. (f) PL decay traces of undoped and doped $\mathrm{CsPb}(\mathrm{Cl}, \mathrm{Br})_{3} \mathrm{NCs}$. 
order of the lattice and the near-unity PLQY as experimentally confirmed (Figure 2a, Figure 3a-c).

Importantly, we find that the strategy shown here can be applied to tuning the photophysical properties of other lead halide perovskite NCs. For instance, doping $2.8 \% \mathrm{Ni}$ into $\mathrm{CsPbCl}_{2.4} \mathrm{Br}_{0.6}$ results in a similar trend to $\mathrm{CsPbCl}_{3}$ in influencing the size and morphology of NCs (Figure 5a-d); the PLQY increases from $1.2 \%$ for $\mathrm{Cs} \mathrm{PbCl}_{2.4} \mathrm{Br}_{0.6}$ to $92.0 \%$ for the doped cousin (Figure 5e, Figure S14). Similarly, doping $2.2 \% \mathrm{Ni}$ into $\mathrm{CsPbCl}_{2} \mathrm{Br}$ leads to a PLQY of $93.1 \%$, much higher than that of undoped NCs (4.8\%) (Figure 5e, Figure $\mathrm{S} 15$ ). Additionally, in both cases, Ni doping greatly lengthens the PL lifetimes and suppresses the nonradiative recombination rates (Figure 5f, Table S3). We note that the concentration of $\mathrm{Ni}$ in these mixed halide perovskite NCs with PLQYs over $90 \%$ is much less than that in $\mathrm{CsPbCl}_{3} \mathrm{NCs}$. This might imply that less dopant is enough to inhibit the formation of structural defects in these mixed halide NCs.

\section{CONCLUSIONS}

To summarize, we have shown that doping of $\mathrm{CsPbX}_{3} \mathrm{NCs}$ with $\mathrm{Ni}$ ions enables single-color violet luminescence with near-unity PLQYs. The combined experimental and theoretical characterizations revealed that the benefit of $\mathrm{Ni}$ doping lies in the increased defect formation energy, resulting in greatly improved short-range order of the perovskite lattice and thus near-unity PLQY. Most excitingly, the concept of dopingenhanced lattice order is not limited to $\mathrm{CsPbCl}_{3} \mathrm{NCs}$, but is applicable to other perovskite systems. This result sheds light on the importance of defects in limiting the performance of perovskite NCs and presents a practical route to eliminate their impact on the optical properties. We therefore envisage that the use of doping engineering to target perovskite nanostructures with near-ideal properties should enable the development of a wide range of high-performance devices such as violet lasers, light-emitting diodes, single-photon sources, and beyond.

\section{EXPERIMENTAL SECTION}

Chemicals. Cesium carbonate $\left(\mathrm{Cs}_{2} \mathrm{CO}_{3}\right.$, Aladdin, $\left.99.99 \%\right)$, lead(II) chloride $\left(\mathrm{PbCl}_{2}\right.$, Alfa Aesar, 99.999\%), nickel(II) chloride hydrate $\left(\mathrm{NiCl}_{2} \cdot x \mathrm{H}_{2} \mathrm{O}\right.$, Alfa Aesar, 99.995\%), oleic acid (OA, Alfa Aesar, tech., 90\%), oleylamine (OAm, Acros, approximate C18content $80-90 \%)$, tri- $n$-octylphosphine (TOP, Alfa Aesar, tech., 90\%), 1-octadecene (ODE, Alfa Aesar, tech., 90\%), and $n$-hexane (Hex, GC, $\geq 98.0 \%$ ) were used. All chemicals were used without purification unless otherwise noted.

Preparation of Cs-Oleate. $\mathrm{Cs}_{2} \mathrm{CO}_{3}(0.4073 \mathrm{~g})$ was loaded into a $50 \mathrm{~mL}$ three-neck flask along with ODE $(15 \mathrm{~mL})$ and $\mathrm{OA}(1.35 \mathrm{~mL})$, dried under vacuum for $1 \mathrm{~h}$ at $120^{\circ} \mathrm{C}$, and then heated under $\mathrm{N}_{2}$ at $150{ }^{\circ} \mathrm{C}$ until all $\mathrm{Cs}_{2} \mathrm{CO}_{3}$ reacted with $\mathrm{OA}$. The final reaction solution was kept at $150{ }^{\circ} \mathrm{C}$ since Cs-oleate precipitates out of ODE at room temperature.

Synthesis of $\mathrm{CsPbCl}_{3}$ and $\mathrm{CsPb}(\mathrm{Cl} / \mathrm{Br})_{3} \mathrm{NCs}$. For the synthesis of $\mathrm{CsPbCl}_{3} \mathrm{NCs}, \mathrm{PbCl}_{2}(0.1322 \mathrm{~g}), \mathrm{ODE}(10 \mathrm{~mL}), \mathrm{OAm}(1.6 \mathrm{~mL})$, OA $(1.6 \mathrm{~mL})$, and TOP $(2 \mathrm{~mL})$ were added into a $50 \mathrm{~mL}$ three-neck round-bottomed flask, dried under vacuum for $1 \mathrm{~h}$ at $120^{\circ} \mathrm{C}$, and then heated under $\mathrm{N}_{2}$ at $120{ }^{\circ} \mathrm{C}$. Meanwhile, dried OAm $(1.6 \mathrm{~mL})$ and dried $\mathrm{OA}(1.6 \mathrm{~mL})$ were subsequently injected into the mixed solution. After $10 \mathrm{~min}$, the temperature was raised to $210^{\circ} \mathrm{C}$ and kept at this temperature for $5 \mathrm{~min}$. Then, the Cs-oleate solution $(0.9 \mathrm{~mL}$, $0.15 \mathrm{M}$ in ODE) was quickly injected, and $60 \mathrm{~s}$ later the reaction mixture was cooled by an ice-water bath. Note that OA and OAm were dried under vacuum for $2 \mathrm{~h}$ at $100{ }^{\circ} \mathrm{C}$, which were named as dried $\mathrm{OA}$ and dried $\mathrm{OAm}$, respectively. The synthesis of $\mathrm{CsPb}$ -
$(\mathrm{Cl}, \mathrm{Br})_{3} \mathrm{NCs}$ was similar to that of $\mathrm{CsPbCl}_{3} \mathrm{NCs}$ except for the use of $\mathrm{PbCl}_{2}$ and $\mathrm{PbBr}_{2}$ with molar ratios of 4:1 and 2:1.

Synthesis of $\mathrm{Ni}$-Doped $\mathrm{CsPbCl}_{3}$ and $\mathrm{CsPb}(\mathrm{Cl}, \mathrm{Br})_{3} \mathrm{NCs}$. For a typical synthesis of doped $\mathrm{CsPbl}_{3} \mathrm{NCs}, \mathrm{PbCl}_{2}(0.1232 \mathrm{~g})$, dried $\mathrm{NiCl}_{2}(0.1146 \mathrm{~g}), \mathrm{ODE}(10 \mathrm{~mL}), \mathrm{OAm}(1.6 \mathrm{~mL}), \mathrm{OA}(1.6 \mathrm{~mL})$, and TOP $(2 \mathrm{~mL})$ were added into a $50 \mathrm{~mL}$ three-neck round-bottomed flask, dried under vacuum for $1 \mathrm{~h}$ at $120^{\circ} \mathrm{C}$, and then heated under $\mathrm{N}_{2}$ at $120{ }^{\circ} \mathrm{C}$. Meanwhile, dried OAm $(1.6 \mathrm{~mL})$ and dried OA $(1.6$ $\mathrm{mL}$ ) were subsequently injected into the mixed solution. After 10 min, the temperature was raised to $210{ }^{\circ} \mathrm{C}$ and kept at this temperature for $5 \mathrm{~min}$. Then, the Cs-oleate solution $(0.9 \mathrm{~mL}, 0.15 \mathrm{M}$ in ODE) was quickly injected, and $60 \mathrm{~s}$ later the reaction mixture was cooled by an ice-water bath. The $\mathrm{Ni}^{2+}$ concentration was tuned by changing the ratio of $\mathrm{PbCl}_{2}$ and $\mathrm{NiCl}_{2}$ from 1:0 to $1: 3$. Note that $\mathrm{NiCl}_{2} \cdot x \mathrm{H}_{2} \mathrm{O}$ was dried under vacuum for $12 \mathrm{~h}$ at $100{ }^{\circ} \mathrm{C}$ to remove water. Ni-doped $\mathrm{CsPb}(\mathrm{Cl}, \mathrm{Br})_{3} \mathrm{NCs}$ were synthesized by using the molar ratios of $\left(\mathrm{PbCl}_{2}+\mathrm{NiCl}_{2}\right): \mathrm{PbBr}_{2}$ of $4: 1$ and 2:1, while keeping all the other parameters unchanged.

Isolation and Purification of Perovskite NCs. The crude solution was cooled with an ice water bath, and aggregated NCs were separated by centrifuging for $5 \mathrm{~min}$ at $12000 \mathrm{rpm}$. After centrifugation, the supernatant was discarded and this process was repeated two more times to remove the residual reaction mixture. Then the particles were redispersed in $4 \mathrm{~mL}$ of hexane and centrifuged again for $5 \mathrm{~min}$ at $12000 \mathrm{rpm}$, and the supernatant was discarded. After repeating the previous step two more times, the precipitate was redispersed in $4 \mathrm{~mL}$ of hexane, the NCs were centrifuged again for $5 \mathrm{~min}$ at $12000 \mathrm{rpm}$, and the supernatant was collected as the final stable colloidal NC solution.

Composition, Structure, and TEM Characterization. The concentrations of lead and nickel ions were determined by using ICPMS (iCAPTM Qc, Thermo Scientific). XRD data were recorded using a Bruker D2 PHASER diffractometer with $\mathrm{Cu} \mathrm{K} \alpha$ radiation $(\lambda=$ $1.54056 \AA$ ). To prepare the samples for the XRD measurement, the $\mathrm{NC}$ solution was evaporated under vacuum at room temperature, and the precipitation was redispersed in toluene to form a concentrated NC solution. The cloudy solution was then drop-cast onto a glass substrate. TEM measurements were performed using a FEI Tecnai G20 S-TWIN TMP microscope operating at an accelerating voltage of $200 \mathrm{kV}$. TEM samples were prepared by dropping a dilute colloidal solution of NCs in a hexane/toluene mixture (1:2) onto the carboncoated copper grids and dried under ambient conditions. Highresolution TEM patterns were collected using a FEI Tecnai G2 F20 STWIN TMP microscope operating at an accelerating voltage of 200 $\mathrm{kV}$. STEM-EDS elemental mapping was obtained using an FEI Talos F200X microscope.

Absorption and Luminescence Characterization. The absorption spectra were taken by a double-beam UV-vis-NIR spectrophotometer (Cary 5000, Agilent). PL spectra were recorded on a spectrometer equipped with continuous $(450 \mathrm{~W})$ xenon lamp (FLS980, Edinburgh Instrument). Room-temperature PLQYs were measured using an integration sphere incorporated into a spectrofluorometer (FluoroLog, Horiba) equipped with a $450 \mathrm{~W}$ xenon lamp. Time-resolved PL measurements were acquired on a Lifespec II setup (Edinburgh Instrument, UK) with the excitation of a picosecondpulsed $373 \mathrm{~nm}$ laser (pulse width: $43 \mathrm{ps}$ ), and the excitation energy density is $4.0 \mu \mathrm{J} / \mathrm{cm}^{2}$. All NC solutions were diluted to an optical density of ca. 0.08 at the corresponding excitation wavelength to minimize the reabsorbance effect. To check whether doped NCs show $\mathrm{PL}$ at longer wavelengths, we also measured the emission spectra by using highly sensitive measurement systems, an iHR550 monochromator equipped with a liquid- $\mathrm{N}_{2}$-cooled $\mathrm{InGaAs}$ detector (SYMPHONY II, 1000-2200 nm, Horiba). We note that no emission was observed in the range of $1000-2200 \mathrm{~nm}$ for doped NCs, under various excitation wavelengths. The detailed methods for the calculation of the average lifetime and radiative and nonradiative decay rates are shown in the Supporting Information.

NMR Characterization. ${ }^{133}$ Cs MAS NMR spectra were recorded with a WB/AVANCE III spectrometer (Bruker), and the resonance frequency was $52.482 \mathrm{MHz}$ for ${ }^{133} \mathrm{Cs}$. Single-pulse excitation was 
used, the MAS rate was $10 \mathrm{kHz}$, and a $0.5 \mathrm{M} \mathrm{CsNO}_{3}$ aqueous solution $\left({ }^{133} \mathrm{Cs}: 0 \mathrm{ppm}\right)$ was used as external standard for the calibration of the chemical shift.

X-ray Absorption Spectroscopy. The X-ray absorption spectra of the $\mathrm{Pb} \mathrm{L}_{\text {III }}$ edge for the $\mathrm{CsPbCl}_{3} \mathrm{NCs}$ and Ni-doped $\mathrm{CsPbCl}_{3} \mathrm{NCs}$ samples were obtained on the 1W2B beamline of the Beijing Synchrotron Radiation Facility with a stored electron energy of 2.5 $\mathrm{GeV}$ and average ring currents of $200 \mathrm{~mA}$. A fixed-exit $\mathrm{Si}(111)$ double-crystal monochromator was used. The NC sample was dispersed on a single-faced adhesive tape (Scotch), which was further sealed with cellulose tape along the edge. This was carried out in a nitrogen-filled glovebox to avoid the adsorption of water molecules or oxygen. Data were collected in the transmission mode at room temperature. The $\mathrm{Pb}$ (Alfa Aesar, 99.9\%) and $\mathrm{PbCl}_{2}$ (Alfa Aesar, 99.999\%) powders were used as reference samples. Before taking measurements, $\mathrm{Pb}$ powder was thermally treated at $150{ }^{\circ} \mathrm{C}$ for $1 \mathrm{~h}$ in a reducing atmosphere $\left(\mathrm{H}_{2} / \mathrm{N}_{2}: 5 \%\right)$ to remove the oxide layer on the surface. The X-ray absorption spectrum of the Ni K-edge for Nidoped $\mathrm{CsPCCl}_{3} \mathrm{NCs}$ was recorded in the fluorescence mode at room temperature and at $85 \mathrm{~K}$. Ni foil, $\mathrm{NiO}$ (Alfa Aesar, 99.998\%), and dried $\mathrm{NiCl}_{2}$ (Alfa Aesar, 99.995\%) powders were used as reference samples, and data were collected in the transmission mode. All X-ray absorption spectra were taken at room temperature. The obtained data were analyzed using the IFEFFIT software package. ${ }^{58}$

DFT Calculations. All calculations are carried out using the VASP with PAW potentials. ${ }^{53,54}$ DFT calculation is performed at a single point at the generalized gradient approximation of Perdew-BurkeErnzerhof (GGA-PBE). The structure relaxations are carried out with a $450 \mathrm{eV}$ plane-wave cutoff. The self-consistent total-energy difference and the convergence criterion for forces on atoms are set to $10^{-4} \mathrm{eV}$ and $0.05 \mathrm{eV} / \AA$, respectively. For k-point integration within the first Brillouin zone, a $3 \times 3 \times 3$ Monkhorst-Pack grid for a $3 \times 3 \times 3$ supercell is selected. On the basis of the static states mentioned above, we calculated the corresponding band structures and DOS, the stability region of different compounds against $\mathrm{Cl}$ and $\mathrm{Pb}$ chemical potentials, and the defect formation energy for both undoped and doped $\mathrm{CsPbCl}_{3}$ supercells. In band structures and DOSs, the zero energy point was set to the Fermi level of the pure $\mathrm{CsPbCl}_{3}$. The system with the defect was corrected by aligning the average electrostatic potential $\left(V_{\mathrm{av}}\right)$ of Cs atoms located far from the defect to the $V_{\text {av }}$ for the same elements in the pure $\mathrm{CsPbCl}_{3}$. To examine the feasibility of incorporating different defects into the lattice, we calculated the formation energy according to the following equations:

$$
\begin{aligned}
& E_{\text {form }}^{\text {doped }}=E_{\text {total }}(\text { Ni doped })-\left[E_{\text {total }}(\text { pure })+\mu_{\mathrm{Ni}}-\mu_{\mathrm{Pb}}\right] \\
& E_{\text {form }}^{\text {vac }}=E_{\text {total }}(\mathrm{X} \text { vac })-\left[E_{\text {total }}(\text { pure })-\mu_{\mathrm{X}}\right] \\
& E_{\text {form }}^{\text {mixed }}=E_{\text {total }}(\text { mixed })-\left[E_{\text {total }}(\text { pure })+\mu_{\mathrm{Ni}}-\mu_{\mathrm{X}}-\mu_{\mathrm{Pb}}\right]
\end{aligned}
$$

where $\mathrm{X}$ represents the chemical elements of $\mathrm{Cs}, \mathrm{Pb}$, or $\mathrm{Cl}$. $E_{\text {form }}^{\mathrm{doped}}$, $E_{\text {form }}^{\mathrm{vac}}$, and $E_{\text {form }}^{\text {mixed }}$ represent dopant formation energy, vacancy formation energy, and mixed defect (that contains dopant and vacancy) formation energy, respectively. $E_{\text {total }}(\mathrm{Ni}$ doped $), E_{\text {total }}(\mathrm{X}$ vac), and $E_{\text {total }}($ mixed) are the total energies of $3 \times 3 \times 3$ supercells of $\mathrm{CsPbCl}_{3}$ containing $\mathrm{Ni}$ dopant, $\mathrm{X}$ vacancy, and mixed defects, respectively. $E_{\text {total }}$ (pure) is the total energy of an undoped $\mathrm{CsPbCl}$ supercell. $\mu_{\mathrm{Cs},}, \mu_{\mathrm{Pb}}, \mu_{\mathrm{C} b}$ and $\mu_{\mathrm{Ni}}$ are the chemical potentials of $\mathrm{Cs}, \mathrm{Pb}$, $\mathrm{Cl}$, and $\mathrm{Ni}$ atoms, respectively. The crystal formation energies $E_{\text {form }}\left[\mathrm{CsPCl}_{3}\right]$ and $E_{\text {form }}\left[\mathrm{CsPbCl}_{3}: \mathrm{Ni}\right]$, can be calculated from the expressions:

$$
\begin{aligned}
& E_{\text {form }}\left[\mathrm{CsPbC}_{3}\right]=E_{\text {total }}(\text { pure })-27 \mu_{\mathrm{Cs}}-27 \mu_{\mathrm{Pb}}-81 \mu_{\mathrm{Cl}} \\
& E_{\text {form }}\left[\mathrm{CsPbCl}_{3} \mathrm{Ni}\right]= E_{\text {total }}(\text { Ni doped })-27 \mu_{\mathrm{Cs}}-26 \mu_{\mathrm{Pb}}-81 \mu_{\mathrm{Cl}} \\
&-\mu_{\mathrm{Ni}}
\end{aligned}
$$

The difference in the crystal formation energy $(\Delta E)$ of $\mathrm{CsPbCl}_{3}: \mathrm{Ni}$ and $\mathrm{CsPbCl}$ thus can be calculated as follows:

$$
\Delta E=E_{\text {total }}(\text { Ni doped })-\left[E_{\text {total }}(\text { pure })+\mu_{\mathrm{Ni}}-\mu_{\mathrm{Pb}}\right]
$$

It is obvious that $\Delta E$ is equal to $E_{\text {form }}^{\text {doped }}$. The stability region of different compounds against $\mathrm{Cl}$ and $\mathrm{Pb}$ chemical potentials was calculated as follows. First, to prevent formation of these elementary substances in the process of synthesis, $\mu_{\mathrm{Cs}}<0 \mathrm{eV}, \mu_{\mathrm{Pb}}<0 \mathrm{eV}$, and $\mu_{\mathrm{Cl}}$ $<0 \mathrm{eV}$ should be satisfied. Second, equilibrium growth of a stable $\mathrm{CsPCl}_{3}$ compound also requires that the chemical potentials should satisfy the following condition:

$$
\mu_{\mathrm{Cs}}+\mu_{\mathrm{Pb}}+3 \mu_{\mathrm{Cl}}=\Delta H\left(\mathrm{CsPbCl}_{3}\right)=-17.806 \mathrm{eV}
$$

where $\Delta H\left(\mathrm{CsPbCl}_{3}\right)$ is the total energy of the $\mathrm{CsPbCl}_{3}$ unit cell.

Lastly, to avoid the formation of the competing binary compounds such as $\mathrm{CsCl}$ and $\mathrm{PbCl}_{2}$, the following constraints should be applied:

$$
\begin{aligned}
& \mu_{\mathrm{Pb}}+2 \mu_{\mathrm{Cl}}<\Delta H\left(\mathrm{PbCl}_{2}\right)=-7.063 \mathrm{eV} \\
& \mu_{\mathrm{Cs}}+\mu_{\mathrm{Cl}}<\Delta H(\mathrm{cscl})=-4.892 \mathrm{eV}
\end{aligned}
$$

where $\Delta H\left(\mathrm{PbCl}_{2}\right)$ and $\Delta H(\mathrm{CsCl})$ are the total energies of $\mathrm{PbCl}_{2}$ and $\mathrm{CsCl}$ unit cells, respectively. With all of these constraints considered, we plotted the available equilibrium chemical potential region for $\mathrm{CsPCCl}_{3}$ as shown in Figure $5 \mathrm{~b}$.

\section{ASSOCIATED CONTENT}

\section{Supporting Information}

The Supporting Information is available free of charge on the ACS Publications website at DOI: 10.1021/jacs.8b04763.

Detailed method for the calculation of the average lifetime, radiative and nonradiative decay rates, STEMEDS elemental mapping, additional TEM images and particle size distribution, additional absorption and PL spectra, PL decay trances and fitted curves, XAFS spectra, additional band structures and DOS, PLQY and ICP-MS results, and other photophysical data (PDF)

\section{AUTHOR INFORMATION}

\section{Corresponding Author}

*timothyhsun@gmail.com

ORCID

Jun-Ying Zhang: 0000-0002-4860-8774

Ya-Meng Chen: 0000-0002-3632-1506

Yang Zhou: 0000-0003-4477-6532

Osman M. Bakr: 0000-0002-3428-1002

Hong-Tao Sun: 0000-0002-0003-7941

\section{Author Contributions}

IIZ.-J. Yong, S.-Q. Guo, J.-P. Ma, and J.-Y. Zhang contributed equally to this work.

\section{Notes}

The authors declare no competing financial interest.

\section{ACKNOWLEDGMENTS}

This work was supported by the National Natural Science Foundation of China (Grant Nos. 11574225 and 51672106), a project funded by the Priority Academic Program Development of Jiangsu Higher Education Institutions (PAPD), and a project supported by State Key Laboratory of Luminescence and Applications. We thank the staff at the 1W2B beamline at the Beijing Synchrotron Radiation Facility for XAFS measurements.

\section{REFERENCES}

(1) Kojima, A.; Teshima, K.; Shirai, Y.; Miyasaka, T. J. Am. Chem. Soc. 2009, 131, 6050-6051. 
(2) Lee, M. M.; Teuscher, J.; Miyasaka, T.; Murakami, T. N.; Snaith, H. J. Science 2012, 338, 643.

(3) Heo, J. H.; Im, S. H.; Noh, J. H.; Mandal, T. N.; Lim, C.-S.; Chang, J. A.; Lee, Y. H.; Kim, H.-j.; Sarkar, A.; Nazeeruddin, M. K.; Grätzel, M.; Seok, S. I. Nat. Photonics 2013, 7, 486-491.

(4) Correa-Baena, J.-P.; Saliba, M.; Buonassisi, T.; Grätzel, M.; Abate, A.; Tress, W.; Hagfeldt, A. Science 2017, 358, 739-744.

(5) Kovalenko, M. V.; Protesescu, L.; Bodnarchuk, M. I. Science 2017, 358, 745-750.

(6) Domanski, K.; Alharbi, E. A.; Hagfeldt, A.; Grätzel, M.; Tress, W. Nat. Energy 2018, 3, 61-67.

(7) Sanehira, E. M.; Marshall, A. R.; Christians, J. A.; Harvey, S. P.; Ciesielski, P. N.; Wheeler, L. M.; Schulz, P.; Lin, L. Y.; Beard, M. C.; Luther, J. M. Sci. Adv. 2017, 3, eaao4204.

(8) Sutherland, B. R.; Sargent, E. H. Nat. Photonics 2016, 10, 295.

(9) Schmidt, L. C.; Pertegás, A.; González-Carrero, S.; Malinkiewicz, O.; Agouram, S.; Mínguez Espallargas, G.; Bolink, H. J.; Galian, R. E.; Pérez-Prieto, J. J. Am. Chem. Soc. 2014, 136, 850-853.

(10) Yang, B.; Chen, J.; Hong, F.; Mao, X.; Zheng, K.; Yang, S.; Li, Y.; Pullerits, T.; Deng, W.; Han, K. Angew. Chem., Int. Ed. 2017, 56, 12471-12475.

(11) Fu, Y.; Zhu, H.; Schrader, A. W.; Liang, D.; Ding, Q.; Joshi, P.; Hwang, L.; Zhu, X.; Jin, S. Nano Lett. 2016, 16, 1000-1008.

(12) Cho, H.; Jeong, S.-H.; Park, M.-H.; Kim, Y.-H.; Wolf, C.; Lee, C.-L.; Heo, J. H.; Sadhanala, A.; Myoung, N.; Yoo, S.; Im, S. H.; Friend, R. H.; Lee, T.-W. Science 2015, 350, 1222-1225.

(13) Sanchez, R. S.; de la Fuente, M. S.; Suarez, I.; MuñozMatutano, G.; Martinez-Pastor, J. P.; Mora-Sero, I. Sci. Adv. 2016, 2, e1501104.

(14) Tan, Z.-K.; Moghaddam, R. S.; Lai, M. L.; Docampo, P.; Higler, R.; Deschler, F.; Price, M.; Sadhanala, A.; Pazos, L. M.; Credgington, D.; Hanusch, F.; Bein, T.; Snaith, H. J.; Friend, R. H. Nat. Nanotechnol. 2014, 9, 687-692.

(15) Protesescu, L.; Yakunin, S.; Bodnarchuk, M. I.; Krieg, F.; Caputo, R.; Hendon, C. H.; Yang, R. X.; Walsh, A.; Kovalenko, M. V. Nano Lett. 2015, 15, 3692-3696.

(16) Yakunin, S.; Protesescu, L.; Krieg, F.; Bodnarchuk, M. I.; Nedelcu, G.; Humer, M.; De Luca, G.; Fiebig, M.; Heiss, W.; Kovalenko, M. V. Nat. Commun. 2015, 6, 8056.

(17) Akkerman, Q. A.; Gandini, M.; Di Stasio, F.; Rastogi, P.; Palazon, F.; Bertoni, G.; Ball, J. M.; Prato, M.; Petrozza, A.; Manna, L. Nat. Energy 2017, 2, 16194.

(18) Tong, Y.; Bladt, E.; Aygüler, M. F.; Manzi, A.; Milowska, K. Z.; Hintermayr, V. A.; Docampo, P.; Bals, S.; Urban, A. S.; Polavarapu, L. Angew. Chem., Int. Ed. 2016, 55, 13887-13892.

(19) Rainò, G.; Nedelcu, G.; Protesescu, L.; Bodnarchuk, M. I.; Kovalenko, M. V.; Mahrt, R. F.; Stöferle, T. ACS Nano 2016, 10, 2485-2490.

(20) Akkerman, Q. A.; Motti, S. G.; Srimath Kandada, A. R.; Mosconi, E.; D’Innocenzo, V.; Bertoni, G.; Marras, S.; Kamino, B. A.; Miranda, L.; De Angelis, F.; Petrozza, A.; Prato, M.; Manna, L. J. Am. Chem. Soc. 2016, 138, 1010-1016.

(21) Huang, H.; Polavarapu, L.; Sichert, J. A.; Susha, A. S.; Urban, A. S.; Rogach, A. L. NPG Asia Mater. 2016, 8, e328.

(22) Su, Y.; Chen, X.; Ji, W.; Zeng, Q.; Ren, Z.; Su, Z.; Liu, L. ACS Appl. Mater. Interfaces 2017, 9, 33020-33028.

(23) Imran, M.; Caligiuri, V.; Wang, M.; Goldoni, L.; Prato, M.; Krahne, R.; De Trizio, L.; Manna, L. J. Am. Chem. Soc. 2018, 140, $2656-2664$.

(24) Liu, F.; Zhang, Y.; Ding, C.; Kobayashi, S.; Izuishi, T.; Nakazawa, N.; Toyoda, T.; Ohta, T.; Hayase, S.; Minemoto, T. ACS Nano 2017, 11, 10373-10383.

(25) Norris, D. J.; Yao, N.; Charnock, F. T.; Kennedy, T. A. Nano Lett. 2001, 1, 3-7.

(26) Pradhan, N.; Peng, X. J. Am. Chem. Soc. 2007, 129, 3339-3347.

(27) Beaulac, R.; Schneider, L.; Archer, P. I.; Bacher, G.; Gamelin, D. R. Science 2009, 325, 973-976.
(28) Sahu, A.; Kang, M. S.; Kompch, A.; Notthoff, C.; Wills, A. W.; Deng, D.; Winterer, M.; Frisbie, C. D.; Norris, D. J. Nano Lett. 2012, 12, 2587-2594.

(29) Abdelhady, A. L.; Saidaminov, M. I.; Murali, B.; Adinolfi, V.; Voznyy, O.; Katsiev, K.; Alarousu, E.; Comin, R.; Dursun, I.; Sinatra, L. J. Phys. Chem. Lett. 2016, 7, 295-301.

(30) Zhou, Y.; Yong, Z.-J.; Zhang, K.-C.; Liu, B.-M.; Wang, Z.-W.; Hou, J.-S.; Fang, Y.-Z.; Zhou, Y.; Sun, H.-T.; Song, B. J. Phys. Chem. Lett. 2016, 7, 2735-2741.

(31) Begum, R.; Parida, M. R.; Abdelhady, A. L.; Murali, B.; Alyami, N. M.; Ahmed, G. H.; Hedhili, M. N.; Bakr, O. M.; Mohammed, O. F. J. Am. Chem. Soc. 2017, 139, 731-737.

(32) Zhu, F.-P.; Yong, Z.-J.; Liu, B.-M.; Chen, Y.-M.; Zhou, Y.; Ma, J.-P.; Sun, H.-T.; Fang, Y.-Z. Opt. Express 2017, 25, 33283-33289.

(33) Nayak, P. K.; Sendner, M.; Wenger, B.; Wang, Z.; Sharma, K.; Ramadan, A. J.; Lovrincic, R.; Pucci, A.; Madhu, P. K.; Snaith, H. J. J. Am. Chem. Soc. 2018, 140, 574-577.

(34) Yamada, Y.; Hoyano, M.; Akashi, R.; Oto, K.; Kanemitsu, Y. J. Phys. Chem. Lett. 2017, 8, 5798-5803.

(35) Liu, W.; Lin, Q.; Li, H.; Wu, K.; Robel, I. n.; Pietryga, J. M.; Klimov, V. I. J. Am. Chem. Soc. 2016, 138, 14954-14961.

(36) Parobek, D.; Roman, B. J.; Dong, Y.; Jin, H.; Lee, E.; Sheldon, M.; Son, D. H. Nano Lett. 2016, 16, 7376-7380.

(37) Huang, G.; Wang, C.; Xu, S.; Zong, S.; Lu, J.; Wang, Z.; Lu, C.; Cui, Y. Adv. Mater. 2017, 29, 29.

(38) Liu, H.; Wu, Z.; Shao, J.; Yao, D.; Gao, H.; Liu, Y.; Yu, W.; Zhang, H.; Yang, B. ACS Nano 2017, 11, 2239-2247.

(39) Xu, K.; Lin, C. C.; Xie, X.; Meijerink, A. Chem. Mater. 2017, 29, $4265-4272$.

(40) Zou, S.; Liu, Y.; Li, J.; Liu, C.; Feng, R.; Jiang, F.; Li, Y.; Song, J.; Zeng, H.; Hong, M.; Chen, X. J. Am. Chem. Soc. 2017, 139, 1144311450 .

(41) Zhou, D.; Liu, D.; Pan, G.; Chen, X.; Li, D.; Xu, W.; Bai, X.; Song, H. Adv. Mater. 2017, 29, 29.

(42) Dong, Y.; Qiao, T.; Kim, D.; Parobek, D.; Rossi, D.; Son, D. H. Nano Lett. 2018, 18, 3716-3722.

(43) McPherson, G.; Stucky, G. J. Chem. Phys. 1972, 57, 37803786.

(44) Becker, M. A.; Vaxenburg, R.; Nedelcu, G.; Sercel, P. C.; Shabaev, A.; Mehl, M. J.; Michopoulos, J. G.; Lambrakos, S. G.; Bernstein, N.; Lyons, J. L.; Stöferle, T.; Mahrt, R. F.; Kovalenko, M. V.; Norris, D. J.; Rainò, G.; Efros, A. L. Nature 2018, 553, 189.

(45) Brennan, M. C.; Herr, J. E.; Nguyen-Beck, T. S.; Zinna, J.; Draguta, S.; Rouvimov, S.; Parkhill, J.; Kuno, M. J. Am. Chem. Soc. 2017, 139, 12201-12208.

(46) Amit, Y.; Eshet, H.; Faust, A.; Patllola, A.; Rabani, E.; Banin, U.; Frenkel, A. I. J. Phys. Chem. C 2013, 117, 13688-13696.

(47) (a) Dalba, G.; Fornasini, P. J. Synchrotron Radiat. 1997, 4, $243-$ 255. (b) Liu, B. M.; Zhang, Z. G.; Zhang, K.; Kuroiwa, Y.; Moriyoshi, C.; Yu, H. M.; Li, C.; Zheng, L. R.; Li, L. N.; Yang, G.; Zhou, Y.; Fang, Y. Z.; Hou, J. S.; Matsushita, Y.; Sun, H. T. Angew. Chem., Int. Ed. 2016, 55, 4967-4971. (c) Liu, B.-M.; Yong, Z.-J.; Zhou, Y.; Zhou, D.-D.; Zheng, L.-R.; Li, L.-N.; Yu, H.-M.; Sun, H.-T. J. Mater. Chem. C 2016, 4, 9489-9498.

(48) Lengeler, B.; Eisenberger, P. Phys. Rev. B: Condens. Matter Mater. Phys. 1980, 21, 4507.

(49) Koller, H.; Burger, B.; Schneider, A. M.; Engelhardt, G.; Weitkamp, J. Microporous Mater. 1995, 5, 219-232.

(50) Reinhold, C. J.; Anderson, P. A.; Edwards, P. P.; Terskikh, V. V.; Ratcliffe, C. I.; Ripmeester, J. A. J. Phys. Chem. C 2008, 112, 17796-17803.

(51) Yin, H.; Tan, W.; Zheng, L.; Cui, H.; Qiu, G.; Liu, F.; Feng, X. Geochim. Cosmochim. Acta 2012, 93, 47-62.

(52) Shannon, R. D. Acta Crystallogr., Sect. A: Cryst. Phys., Diffr., Theor. Gen. Crystallogr. 1976, 32, 751-767.

(53) Kresse, G.; Furthmüller, J. Phys. Rev. B: Condens. Matter Mater. Phys. 1996, 54, 11169.

(54) Kresse, G.; Joubert, D. Phys. Rev. B: Condens. Matter Mater. Phys. 1999, 59, 1758. 
(55) Kang, J.; Wang, L.-W. J. Phys. Chem. Lett. 2017, 8, 489-493.

(56) Li, Y.; Zhang, C.; Zhang, X.; Huang, D.; Shen, Q.; Cheng, Y.; Huang, W. Appl. Phys. Lett. 2017, 111, 162106.

(57) Adinolfi, V.; Yuan, M.; Comin, R.; Thibau, E. S.; Shi, D.; Saidaminov, M. I.; Kanjanaboos, P.; Kopilovic, D.; Hoogland, S.; Lu, Z. H. Adv. Mater. 2016, 28, 3406-3410.

(58) Ravel, B.; Newville, M. J. Synchrotron Radiat. 2005, 12, 537541. 